\title{
Introduction to the minisymposium on sports imaging in children
}

\author{
Marc S. Keller
}

Received: 17 September 2009 / Accepted: 29 September 2009 /Published online: 22 October 2009

(C) Springer-Verlag 2009

The importance of children's involvement in athletics has been emphasized in recent years by The President's Council on Physical Fitness and Sports through the United States Department of Health and Human Services, representing one of many countries seeking to improve the health of children through physical activity [1]. The benefits of organized sports for young people are well recognized, including increasing physical conditioning, improving skills, acquiring confidence, gaining a healthy attitude toward competition, winning and losing as well as learning to participate as a team member.

Injuries do occur and are part of athletics. The minisymposium on sports imaging in children addresses a variety of events arising from the participation of youngsters in basketball, football, soccer and gymnastics. Understanding the patterns and mechanisms of injury in each sport is important in knowing when and how to use imaging in the young athlete's care. Not every injury merits imaging, and learning this is also key. For the radiologists, we wish to emphasize that, as in other areas of pediatric imaging, the patterns of biomechanical susceptibility in response to stresses upon the immature musculoskeletal system may be quite different from those in adults.

Each of the authors is also a parent who has had to consider allowing a child to participate in various sports.
Part of our aim is to provide a resource, not only for healthcare personnel, but also for parents searching for information about injuries and risks in considering their own child's athletic participation. Accordingly, some of the comments address entities that are not directly related to imaging but were thought by authors to be relevant to a complete discussion of the sport and the young people who participate.

The authors have had the experience and pleasure during several years of working together as a team on this project, having been invited to present versions of this symposium as an organized course at a number of meetings. During the last few years, we have learned much from one another and have modified our material in response to comments from our audiences. We are very happy that Pediatric Radiology has chosen to preserve our efforts as a resource that others may find helpful for some years to come.

\section{Reference}

1. (2009) The President's Council on Physical Fitness and Sports. Resources. Available via http://www.fitness.gov/home_resources. htm. Accessed 15 Sept 2009
M. S. Keller $(\triangle)$

Department of Radiology,

The Children's Hospital of Philadelphia,

34th Street and Civic Center Boulevard,

Philadelphia, PA 19104, USA

e-mail: kellerm@email.chop.edu 